\title{
The Effects of Notch Size and Material Microstructure on the Notch Sensitivity Factor for Notched Components
}

\author{
Gbadebo Owolabi*, Oluwamayowa Okeyoyin, Oluwakayode Bamiduro, Horace \\ Whitworth
}

Department of Mechanical Engineering, Howard University, Washington, DC, U

\begin{abstract}
Nickel base superalloys are used in hot sections of gas turbine engines due to its high strength and good creep, fatigue, and corrosion resistance at high temperature. In this paper, a new probabilistic approach based on weakest-link theory that accounts for the effects of the microstructure, notch size and notch acuity is described and applied to nickel base superalloy to determine the fatigue notch factor, notch sensitivity index and the probability of forming microstructurally small crack from the notch root. The simulation results obtained from this framework are compared with experimental results and results obtained using existing classical methods for notched polycrystalline nickel base superalloys for the different notch root radii and acuities considered.
\end{abstract}

Keywords: nickel base superalloy, non-metallic inclusions, probabilistic framework, fatigue notch factor, crystal plasticity

\section{Introduction}

Nickel base superalloy is a high performance material subjected to severe operating conditions. It is widely used in aero engine components and powerplants because of its high strength and good creep, fatigue and corrosion resistance at high temperatures [1-2]. Fatigue failure is of great importance for these components for the catastrophic consequence caused by cyclic stresses and strains. Fatigue failure of nickel-base superalloy is a limiting factor for their reliable use in many engineering applications. Most of the prior research studies on the fatigue behavior of nickel-base superalloy are focused on higher length-scale phenomena and on direct experimental observation of the fatigue damage processes [3]. Under high cycle fatigue (HCF) situation, crack nucleation and microstructurally small crack growth is highly heterogeneous at the grain scale and the influence of

\footnotetext{
* Corresponding author. Tel.: 1-202-806-6594; fax: 1-202-483-1396

E-mail address:gbadebo.owolabi@ howard.edu
} 
microstructure on small crack formation and growth has been shown to play a significant role [4].

Microstructure features such as inclusions, pores, the grain size distribution, the grain boundaries, the precipitate size distribution, and volume fraction often have main influences in determining the crack formation and growth in both low cycle fatigue (LCF) and HCF in nickel-base superalloys [5]. Since polycrystalline IN 100 is prepared by powder metallurgy (PM) technique, inclusions and pores in microstructure always provide crack nucleation sites [5]. The presence of inclusions within a grain or near grain boundaries and pores in a polycrystalline material can significantly reduce the number of cycles to form a fatigue crack because the incompatibility of deformations between the inclusions and the surrounding materials leads to local plasticity [6]. Hyzak and Bernstein [7] and Deybal et. al. [8] have established the important roles played by inclusions in the formation and propagation of fatigue crack in nickel base superalloys while considering two PM nickel base superalloys.

One major problem common with fatigue research of these materials with complex microstructures is the scatter in fatigue life or fatigue strength for similar experiments conducted under the same operating conditions. Prior studies have shown that larger amount of scatter exists in the early stages of crack growth due to the microstructural variability and relatively little scatter in the large crack growth stage [9]. Due to this inherent scatter involved in $\mathrm{HCF}$, numerous probabilistic approaches have been developed in HCF lifing strategies. Deyber et al. [10] proposed a probabilistic framework using statistical distribution of particle size. The authors considered two different modes of fatigue crack initiation in the DA 718: Fatigue micro-crack formation on second phase particles (carbides and nitrides) of less than $10 \mu \mathrm{m}$ grain size and transgranular stage I initiation of fatigue crack along favorably oriented slip bands. The resulting probability of failure based on crack formation at particle interfaces is given as:

$$
P_{f}\left(\sigma_{d}\right)=1-\exp \left(-\left[\frac{\Sigma_{1}+\lambda\left\langle\sigma_{e q}-\sigma_{y}\right\rangle}{\sigma_{0}}\right]^{m}\right)
$$

where $\Sigma_{1}$ is the maximum principal stress, $\lambda$ is the particle shape factor, $\sigma_{\text {eq }}$ is the equivalent Mises stress, $\sigma_{\mathrm{y}}$ is the yield stress, and $\sigma_{0}$ is the scaling parameter. Deyber et. al. [10] also proposed a model for crack propagation based on Tomkins model [11] given as:

$$
\frac{d a}{d N}=\alpha \cdot a, \text { where } \alpha=\frac{\pi^{2}}{8} \frac{\Delta \varepsilon_{p} \Delta \sigma^{2}}{(2 T)^{2}}\left(1+\frac{\pi^{2}}{8}\left(\frac{\Delta \sigma}{2 T}\right)^{2}\right)
$$


where $T$ is the ultimate tensile stress in the damage process zone of the crack, $\Delta \varepsilon_{\mathrm{p}}$ is the plastic strain amplitude, $\Delta \sigma$ is the maximum principal stress amplitude. Based on the model, the probability that a particle of diameter $D_{0}$ will propagate, in a potential number of cycles $\left(N_{0}\right)$, was determined. The probability of failure is assumed to be equal to the probability of finding a particle of size greater that the potential particle size, $D_{0}$. The overall global probability of failure is taken as the combined product of the probabilities of failure at the surface, subsurface and within the bulk of the material and given as:

$$
P_{f}=1-\left\{\begin{array}{l}
\prod_{n=1}^{\text {Nel,surf }}\left[\left(1-P_{f}\left(\sigma_{d}\right) P\left(D \geq D_{0}\right)\right)^{N_{p, s u f f}}\right] \\
* \prod_{n=1}^{\text {Nel,subsurf }}\left[\left(1-P_{f}\left(\sigma_{d}\right) P\left(D \geq D_{0}\right)\right)^{N_{p, \text { subsurf }}}\right] \\
* \prod_{n=1}^{\text {Nel,bulk }}\left[\left(1-P_{f}\left(\sigma_{d}\right) P\left(D \geq D_{0}\right)\right)^{N_{p, b u l k}}\right]
\end{array}\right\}
$$

Where $P_{f}\left(\sigma_{d}\right)$ is given in Eq. (1), $N_{\mathrm{p}}$ and $N_{\mathrm{el}}$ are the number of particles contained in the meshed elements in each location (surface, subsurface and bulk).

Based on known microstructure of PM nickel base superalloy, Pineau [12] proposed a probabilistic framework that employs the statistical distribution of inclusion sizes to determine probability of failure of different components. The proposed model considers both surface and volume defects and the propagation of defects to a critical size. The resulting probability that any one inclusion intercept a free surface for uniform size distribution of spherical inclusion is given as [12]:

$$
P_{\text {surf }}(D, n, S, V)=1-\left(1-\frac{D S}{V}\right)^{n V}
$$

where $D$ is the inclusion diameter, $S$ is the highly stressed surface area, $V$ is the volume of the specimen, and $n$ is the number of inclusions per unit volume. However, for varying inclusion sizes grouped into classes, the probability that inclusion of size class $k$ intercept a free surface for distribution of inclusions sizes is given as:

$$
P_{k, \text { surf }}\left(D_{k}, n_{k}, S, V\right)=1-\left(1-\frac{D_{k} S}{V}\right)^{n_{k} V}
$$

Pineau [12] used the model to estimate the probability of failure of three different sized components made from Rene 95 and established that probability of failure is highly size dependent. 
Existing probabilistic framework models account for stress heterogeneity effect using the concept of effective volume. Doudard et al. [13] extended this concept to account for multiaxial loading histories in HCF by introducing a factor to represent the distribution of activated slip directions and also captures the variability of the activation level. In this approach, it is assumed that slip directions become active when the shear stress amplitude $T_{a}$ exceeds the critical yield strength. Doudard et al. [13] used Poisson point process [14-15] to describe the activation and the average density of active sites $\lambda$ is given as:

$$
\lambda=\frac{1}{V_{0} S_{0}^{m}} \int\left(2 T_{a}\right)^{m} d \Theta
$$

where $\mathrm{m}, \mathrm{V}_{0}$ is the reference volume and $V_{0} S_{0}^{m}$ are material-dependent parameters. Equation (6) is integrated over all possible angles to account for all the space directions defined by the solid angle $\Theta$. Doudard et al. [13] defined the probability $\mathrm{P}_{\mathrm{k}}$ (within a domain $\Omega$ of volume $\mathrm{V}$ ) of finding $\mathrm{k}$ active sites as:

$$
P_{k}=\frac{[N(\Omega)]^{k}}{k !} \exp [-N(\Omega)]
$$

Where $N(\Omega)$ is the average number of active sites given as:

$$
N(\Omega)=\lambda V
$$

The resulting probability of failure $\mathrm{P}_{\mathrm{f}}$ is given as:

$$
P_{f}=1-\exp \left[-\frac{1}{V_{0}} \int\left(\frac{2 T_{a}}{S_{0}}\right)^{m} \cos (\zeta) d \Theta d V\right]
$$

This probabilistic framework can be used for both non-proportional loadings and multiaxial loading. It also accounts for scatter in HCF fatigue data through the distribution of the slip system and the variability in the slip system activation level. Flaceliere and Morel [16] developed a probabilistic framework based on the endurance criterion proposed by Papadopoulos [17] which defined the equivalent stress as a function of the quadratic mean value of resolved shear stress $T_{a}$ and the maximum hydrostatic pressure as:

$$
\sigma_{e q}=M_{\sigma}+p \sum_{H, \text { max }}
$$


where $M_{\sigma}$ is the quadratic mean value of resolved shear stress $T_{a}, p$ is the coefficient reflecting the sensitivity to hydrostatic stress and $\Sigma_{\mathrm{H} \text {,max }}$ is the maximum hydrostatic pressure over a loading period. This equivalent stress is applicable to any complex stress states (in-phase or out of phase loading). The probability of failure is given as:

$$
P_{f}=1-\exp \left[-\frac{1}{V_{0}} \int_{v} \frac{\sqrt{\left\langle T_{a}^{2}\right\rangle}+p \sigma_{H, \max }}{\sigma_{0}} d V\right]
$$

where $V_{0}$ is the reference volume and $\sigma_{0}$ is the damage threshold stress level. Flaceliere and Morel [16] also investigated the stress gradient and surface effects in probabilistic fatigue failure. Based on Papadopoulos proposal [17], they used an equivalent stress function dependent on the normalized gradient of the maximum hydrostatic stress given as:

$\sigma_{e q, S}=M_{\sigma}+p\left(1-\beta\left\langle\frac{G}{\sum_{H, \max }}\right)^{n}\right) \sum_{H, \max }$

with

$G=\sqrt{\left(\frac{\partial \sum_{H, \max }}{\partial x}\right)^{2}+\left(\frac{\partial \sum_{H, \max }}{\partial y}\right)^{2}+\left(\frac{\partial \sum_{H, \max }}{\partial z}\right)^{2}}$

where $\mathrm{n}$ is a constant assumed to be 1 while $\beta$ is a normalized hydrostatic stress intensity factor. The surface stress Weibull function is then defined as:

$$
P_{f}\left(\sigma_{e q, S}\right)=1-\exp \left[-\frac{1}{S_{0}} \int_{s} \frac{\sigma_{e q, S}\left(\sigma, G\left(\sigma_{H, \max }\right)\right)}{\sigma_{0}} d S\right]
$$

The results demonstrated a good correlation between the surface model approach and the experimentally determined failure probability for GS52 nodular cast iron and C36 mild steel. However, wide discrepancies were noted between the surface and volume approaches when applied to the nodular cast iron due to the presence of pores ranging in size from 50-1000 $\mu \mathrm{m}[16]$.

Delahay and Palin-Luc [18] developed a probabilistic approach for high cycle multiaxial fatigue by the combination of a three-parameter Weibull distribution with the deterministic energy-based and volumetric high-cycle multiaxial fatigue 
criterion proposed by Banvillet et al. [19-20]. To account for the multiaxiality of the stresses, the Weibull stress is replaced by the strain work density per loading cycle. The resulting failure probability is given as:

$$
P_{f}(V, \sigma)=1-\exp \left[-\frac{1}{V_{0}} \int_{v}\left(\frac{\left\langle W_{g}-W_{g}^{*}\right\rangle}{W_{u}}\right)^{m} d V\right]
$$

Where $W \mathrm{~g}$ is the strain work density given to the material per loading period, $W_{g}^{*}$ is the threshold value of $W \mathrm{~g}, W \mathrm{u}$ is a scale parameter and $m$ is the Weibull slope. The predictions by the probability framework are in good agreement with experimental probability distribution when applied to five materials investigated: the $30 \mathrm{NiCrMo} 16$ and $35 \mathrm{CrMo} 4$ quenched and tempered steels, the $\mathrm{C} 20$ annealed steel, the EN-GJS800-2 nodular cast iron and the Ti-6Al-4V titanium alloy. Delahay and Palin-Luc [18] also investigated the size-effect which is usually linked to stressstrain gradient in HCF as shown by Papadopoulos [17] and they gave the probability of failure in fully reversed tension for a smooth component as:

$$
P_{f}\left(V, \sigma_{a}\right)=1-\exp \left[-\frac{V}{\varphi_{u}}\left\langle\frac{\left(\sigma_{a}\right)^{2}}{E}-W_{g}^{*}\right\rangle^{m}\right]
$$

where $V$ is the component volume, $\sigma_{\mathrm{a}}$ is the normal stress amplitude, $E$ is the young modulus, and

$$
\varphi_{u}=V_{0} W_{u}^{m}
$$

In addition to materials defects which can be accounted for using some of the probabilistic framework, most engineering components have structural geometric discontinuities. These discontinuities can be in the form of keyways, weld fillets, holes for bolts, and rivets. For nickel base superalloy used in turbine engine, the turbine engine operates at a very high temperature and thus the blades have tiny holes for cooling purposes. The coolants are forced through the holes at high pressure for cooling of the system [21]. These holes serve as areas of stress concentration and are typical locations for localized micro-plasticity thus reducing the fatigue strength of the material when subjected to cyclic loading. The holes also serve as favorable zones for crack initiation leading to early retirement of the turbine blade and engine as shown in Figure 1. Notches and inclusions therefore form part of the major factors that dictate the fatigue strength of the components. Hence, a robust fatigue assessment model which includes effects of both material 
and geometric discontinuities on the fatigue strength of the components would be of great importance in predicting the fatigue life and in the process of developing optimized, safe, and reliable structural components.

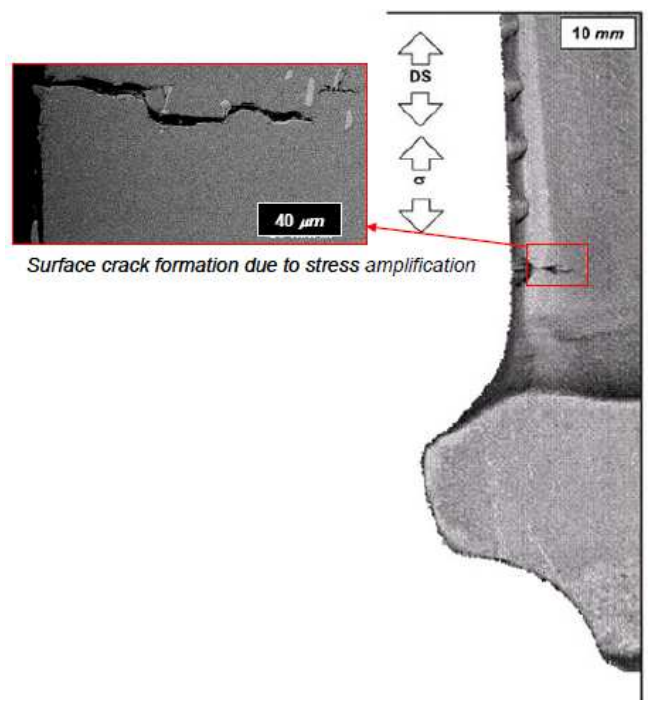

Fig. 1: Crack Initiation at cooling hole of turbine blade [22]

The geometric discontinuities are usually modeled as notches with a certain depth and notch root radius to investigate their effects on the fatigue life of components subjected to cyclic loading [23-24]. The resulting notch effect is characterized using a fatigue strength reduction factor also known as the fatigue notch factor, $\mathrm{k}_{\mathrm{f}}$. Based on different assumptions, several models have been developed for $\mathrm{k}_{\mathrm{f}}$ in the past. The Neuber [25], the Kuhn et al. [26], the Peterson [27], the Heywood [2829], the Buch [30-31], and the Siebel et al. [32] equations are based on an average stress assumption. The average stress assumption stipulates that fatigue failure will occur given that the average stress over a length scale in the vicinity of the notch root is equal to the smooth specimen fatigue limit. Other existing equations for $\mathrm{k}_{\mathrm{f}}$ include: Ting et al. [33], and Yu et al. [34] that are based on fracture mechanics models and the Sheppard [35] model that is based on stress field intensity models.

It is important to study the interactions between both material and geometric defects in predicting the fatigue damage of components having a combination of these defects. At present, however, there is no simulation-based methodology for modeling the interactive effects of stress/strain field gradients at the notch-root and microstructure-scale behavior in predicting notch-root fatigue failure in service loads where performance outweighs other considerations. In this paper, the concept of fatigue notch factor and its associated notch sensitivity is effectively extended to incorporate microstructure sensitivity for notched components using 
an approach that combines computational crystal plasticity with probabilistic mesomechanics. The framework involves computational crystal plasticity modeling of the notched components with and without non-metallic inclusions to obtain three dimensional perspectives of stress distributions in the notch root and inclusions regions. The stress distributions around these discontinuities are then used in the new probabilistic micromechanics-based model that accounts for the effects of nonlocal notch root plasticity, loading microstructural variability, and extrinsic defects on local cyclic plasticity at the microstructure-scale level to predict the fatigue notch factor and the probability of formation of microstructurally small cracks. This approach can reduce the amount of testing required to make design decisions on material or component reliability by systematically estimating the scatter of fatigue life associated with microstructure variations through the use of simulations.

\section{Crystal Plasticity Models}

The crystal plasticity constitutive model developed by Mahesh [36] is used in this work. Rate dependent method is employed for the model because as the temperature increases, strain rate effects become increasingly important. Physically-based hardening models are employed on the basis of dislocationprecipitate interactions under strengthening caused by dislocation interactions. The shearing rate on each slip system is expressed as [36]:

$$
\dot{\gamma}^{\alpha}=\dot{\gamma}_{1}\left\langle\frac{\left|\tau^{\alpha}-\chi^{\alpha}\right|-\kappa^{\alpha}}{D^{\alpha}}\right\rangle^{n_{1}}+\dot{\gamma}_{2}\left\langle\frac{\left|\tau^{\alpha}-\chi^{\alpha}\right|}{D^{\alpha}}\right\rangle^{n_{2}} \operatorname{sgn}\left(\tau^{\alpha}-\chi^{\alpha}\right)
$$

where $\dot{\gamma}_{1}$ and $\dot{\gamma}_{2}$ are constants, the flow exponents are represented as $\mathrm{n}_{1}$ and $\mathrm{n}_{2}, \kappa^{\alpha}$ is the slip resistance on each slip system and it is called the mechanical threshold [37], $D^{\alpha}$ is the average drag resistance, $\chi^{\alpha}$ is the back stress on each slip system. The back stress, unlike for pure single crystal, are very important component for two phase materials such as nickel base superalloys and thus cannot be neglected [38]. It is also important to note that the back stress is subtracted from the applied shear stress to reflect the net force responsible for driving the dislocation. The threshold stress accounts for the anomalous yield behavior of the $\gamma-\gamma$ nickel base superalloy, i.e, the increase in yield stress resulting from increase in temperature in the intermediate temperature range.

The first part of Eq. (18) accounts for the dominant cyclic behavior where the threshold stress plays the role of the yield stress. Conversely, the second part of Eq. (18) accounts for the effect of creep thermally activated at lower stresses. When the first term is not active, especially at lower stresses, matrix faulting and 
dissociation of heterogeneous plastic dislocation control the dominant flow mechanism. Complex cyclic stress-strain history like that of nickel base superalloy is best modeled by the two term flow rule presented in Eq. (18). A total of 18 slip systems are used to model dislocation motion within the matrix of the nickel base superalloy; 12 octahedral slip systems and 6 cube slip systems. A list of the slip systems is provided in Table 1 .

Table 1: Slip systems in nickel base superalloy [36]

\begin{tabular}{lllll}
\hline $\begin{array}{l}\text { Slip System } \\
\alpha\end{array}$ & $\begin{array}{l}\text { Octahedral Slip } \\
\text { Slip Plane }\end{array}$ & Slip Direction & $\begin{array}{l}\text { Cube Slip } \\
\text { Slip Plane }\end{array}$ & Slip Direction \\
\hline 1 & $\{111\}$ & $\langle 01 \overline{1}\rangle$ & $\{100\}$ & $\langle 011\rangle$ \\
2 & $\{111\}$ & $\langle\overline{1} 01\rangle$ & $\{100\}$ & $\langle 01 \overline{1}\rangle$ \\
3 & $\{111\}$ & $\langle 1 \overline{1} 0\rangle$ & $\{010\}$ & $\langle 101\rangle$ \\
4 & $\{1 \overline{1} \overline{1}\}$ & $\langle 0 \overline{1} 1\rangle$ & $\{010\}$ & $\langle 10 \overline{1}\rangle$ \\
5 & $\{1 \overline{1} \overline{1}\}$ & $\langle\overline{1} 0 \overline{1}\rangle$ & $\{001\}$ & $\langle 110\rangle$ \\
6 & $\{1 \overline{1} \overline{1}\}$ & $\langle 110\rangle$ & $\{001\}$ & $\langle\overline{1} 10\rangle$ \\
7 & $\{\overline{1} 1 \overline{1}\}$ & $\langle 011\rangle$ & & \\
8 & $\{\overline{1} 1 \overline{1}\}$ & $\langle 10 \overline{1}\rangle$ & & \\
9 & $\{\overline{1} 1 \overline{1}\}$ & $\langle\overline{1} \overline{1} 0\rangle$ & & \\
10 & $\{\overline{1} \overline{1} 1\}$ & $\langle 0 \overline{1} \overline{1}\rangle$ & & \\
11 & $\{\overline{1} \overline{1} 1\}$ & $\langle 101\rangle$ & & \\
12 & $\{\overline{1} \overline{1} 1\}$ & $\langle\overline{1} 10\rangle$ & & \\
\hline
\end{tabular}

The 12 octahedral slip systems are active at low temperatures within the $\gamma$ matrix which is typical of a FCC lattice structure. However, at high temperatures and high resolved shear stresses, the 6 cube slip systems are activated in the $\gamma$ phase though their role is not yet well understood and characterized. Taylor relation is assumed for the hardening of the threshold stress on each of the slip system and it is expressed as [36]:

$$
\kappa^{\alpha}=\kappa_{0}^{\alpha}+\alpha_{t} \tilde{\mu} \tilde{b} \sqrt{\rho^{\alpha}}
$$

where each slip system dislocation density is represented as $\rho^{\alpha}$ (for both cube and octahedral slip systems), $\tilde{\mu}$ is the shear modulus, $b$ is the effective burgers vector, 
and $\alpha$ is a coefficient that accounts for the statistical arrangement of the dislocation population.

The shear modulus in Eq. (19) is governed by the rule of mixtures and expressed as:

$$
\tilde{\mu}=\left(f_{p 1}+f_{p 2}+f_{p 3}\right) \mu_{\gamma}+f_{m} \mu_{m}
$$

wher $f_{p 1}, f_{p 2}, f_{p 3}$ are the volume fractions of the three $\gamma^{\prime}$ matrix phases respectively i.e., primary, secondary and tertiary while $f_{m}$ is the volume fraction of the matrix phase. Also the effective burgers vector is expressed as:

$\tilde{b}=\left(f_{p 1}+f_{p 2}+f_{p 3}\right) b_{\gamma}+f_{m} b_{m}$

where $b_{\gamma}$ is the burger vector of the $\gamma^{\prime}$ precipitates and $b_{m}$ is the burger vector of the matrix.

The initial critical resolved shear stress $\kappa_{0, \lambda}^{\alpha}$ given by Heilmaier et. al. [39] and Reppich et al. [40] is expressed as:

$$
\begin{aligned}
& \boldsymbol{\kappa}_{0, \text { oct }}^{\alpha}=\left[\left(\tau_{0, o c t}^{\alpha}\right)^{n_{\kappa}}+\Psi_{o c t}\left(f_{p 1}, d_{2}, f_{p 2}, d_{3}, f_{p 3}\right)^{n_{\kappa}}\right]^{1 / n_{\kappa}}+\left(f_{p 1}+f_{p 2}\right) \tau_{n s}^{\alpha} \\
& \boldsymbol{\kappa}_{0, c u b}^{\alpha}=\left[\left(\tau_{0, c u b}^{\alpha}\right)^{n_{\kappa}}+\Psi_{c u b}\left(f_{p 1}, d_{2}, f_{p 2}, d_{3}, f_{p 3}\right)^{n_{\kappa}}\right]^{1 / n_{\kappa}}
\end{aligned}
$$

where,

$\Psi_{o c t}=\Psi_{c u b}=\left[c_{p 1} \sqrt{\zeta \frac{f_{p 1}^{\prime}}{d_{1}}}+c_{p 2} \sqrt{\zeta \frac{f_{p 2}^{\prime}}{d_{2}}}+c_{p 3} \sqrt{\zeta f_{p 3}^{\prime} d_{3}}+\frac{c_{g r}}{\sqrt{d_{g r}}}\right]$

In Eq. (23), $\zeta=\frac{\Gamma_{A P B}}{\Gamma_{A P B, r e f}}$, where $\Gamma_{A P B}$ is the anti-phase boundary energy. The primary, secondary and tertiary gamma prime precipitate sizes are represented by $d_{1}, d_{2}$ and $d_{3}$ respectively while the grain size is denoted as $d_{g r} . f_{p 1}^{\prime}, f_{p 2}^{\prime}$ and $f_{p 3}^{\prime}$ are the normalized precipitate volume fractions. The value of exponent $n_{\kappa}$ ranges from 
1 to 1.2 and the values of $c_{\mathrm{p} 1}, \mathrm{c}_{\mathrm{p} 2}, \mathrm{c}_{\mathrm{p} 3}$ and $\mathrm{c}_{g r}$ are determined by curve fitting the initial yield strength to the experimentally determined values.

Based on the work of Qin et al. [41-42] and Shenoy et al. [43], the non-schmid stress, $\tau_{n s}^{\alpha}$, dependence of the octahedral slip systems is expressed as:

$\tau_{n s}^{\alpha}=h_{p e} \tau_{p e}^{\alpha}+h_{c b}\left|\tau_{c b}^{\alpha}\right|+h_{s e} \tau_{s e}^{\alpha}$

Here the resolved shear stress on the primary, secondary and cube slip systems are denoted by $\tau_{p e}^{\alpha}, \tau_{s e}^{\alpha}$ and $\tau_{c b}^{\alpha}$ respectively while $h_{p e}, h_{c b}, h_{s e}$ are constants.

Feaugas and Haddou [44] have identified a direct proportionality between the rate of dislocation recovery and the dislocation density. Thus, the evolution of the dislocation density is expressed as [45]:

$\dot{\rho}_{\lambda}^{\alpha}=h_{0}\left\{Z_{0}+k_{1} \sqrt{\rho_{\lambda}^{\alpha}}-k_{2} \rho_{\lambda}^{\alpha}\right\}\left|\dot{\gamma}^{\alpha}\right|$

and

$$
Z_{0}=\frac{k_{\delta}}{\tilde{b} d_{\delta e f f}}, \quad d_{\delta e f f} \approx\left(\frac{2}{d_{2 \delta}}\right)^{-1}
$$

where $k_{1} \sqrt{\rho_{\lambda}^{\alpha}}$ is the dislocation storage and $k_{2} \rho_{\lambda}^{\alpha}$ is the dynamic recovery. $k_{1}, k_{2}$ and $k_{\delta}$ are constants, $d_{2 \delta}$ is the secondary precipitate spacing and $d_{\delta e f f}$ is the equivalent precipitate spacing. The hardening coefficient $h_{0}$ for cube and octahedral slip systems are 2.4 and 4.8 respectively.

The back stress is used to capture the effects of Bauschinger effect and it is expressed as [45]:

$$
\dot{\chi}_{\lambda}^{\alpha}=C_{\chi}\left\{\eta \tilde{\mu} \tilde{b} \sqrt{\rho_{\lambda}^{\alpha}} \operatorname{sgn}\left(\tau^{\alpha}-\chi_{\lambda}^{\alpha}\right)-\chi_{\lambda}^{\alpha}\right\}\left|\dot{\gamma}^{\alpha}\right|
$$

and

$$
\eta=\frac{\eta_{o} Z_{o}}{Z_{o}+k_{1} \sqrt{\rho_{\lambda}^{\alpha}}}
$$

where $C_{\alpha}$ is a fitting parameter and $\eta$ reflects the relative proportion of geometrically necessary dislocations to total dislocation density. 


\section{Microstructure-Characterization}

The alloy used in this study is the polycrystalline nickel base superalloy, IN 100, which is used extensively for intermediate temperature $\left(\sim 650^{\circ} \mathrm{C}\right)$ applications such as turbine engine. Nickel base superalloys are strengthened through solid solution strengthening of the $\gamma$ matrix and precipitation strengthening using ordered FCC $\gamma$ precipitate in the austenitic $\gamma$ matrix. Non-metallic inclusions and pores are also present as minor phases depending on the alloy chemistry and heat treatment. The strength of IN100 is highly dependent on a number of interrelated microstructure features including the inclusion size distribution, the grain sizes of the $\gamma$ matrix and the $\gamma^{\prime}$ precipitate phases. IN100 has been well characterized in the work of Wusatowska-Sarnet et al. [46] and Jha et al. [47]. Figure 2 shows typical microstructural features of IN 100. The distribution of the non-metallic inclusions in the IN100 is shown in Fig. 3a. Figure 3a shows that some inclusions are located at the grain boundaries while others lie predominantly within the grains. The size distributions of the non-metallic inclusions are shown in Fig. 3 b. These data will serve as inputs in the construction of the microstructures for the finite element analysis in Section 4.
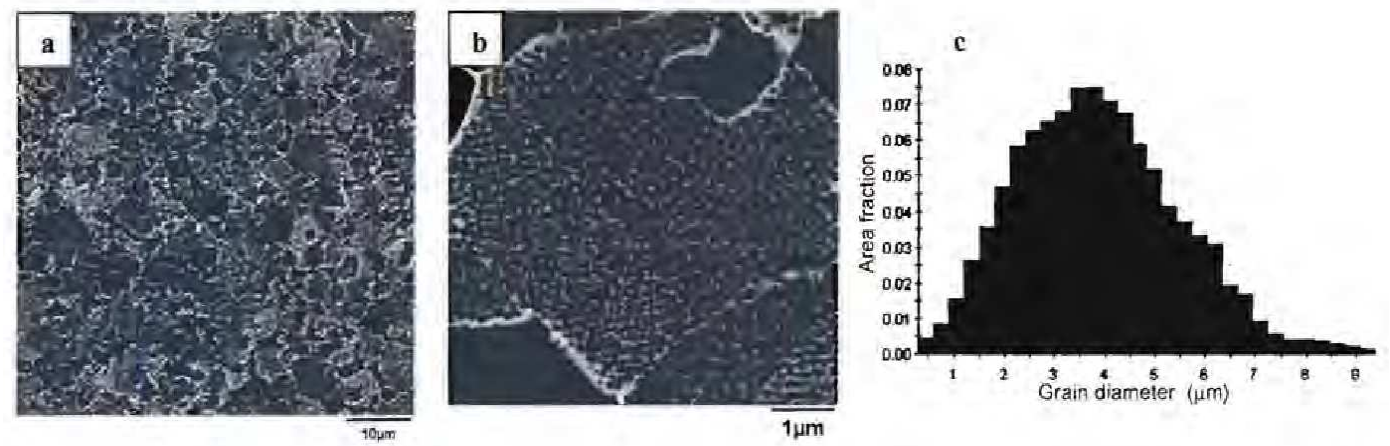

Fig. 2: (a) the $\gamma$ and the primary $\gamma^{\prime}$ structure, (b) the secondary $\gamma^{\prime}$ morphology, and (c) the $\gamma$ grain size distribution [47]. 

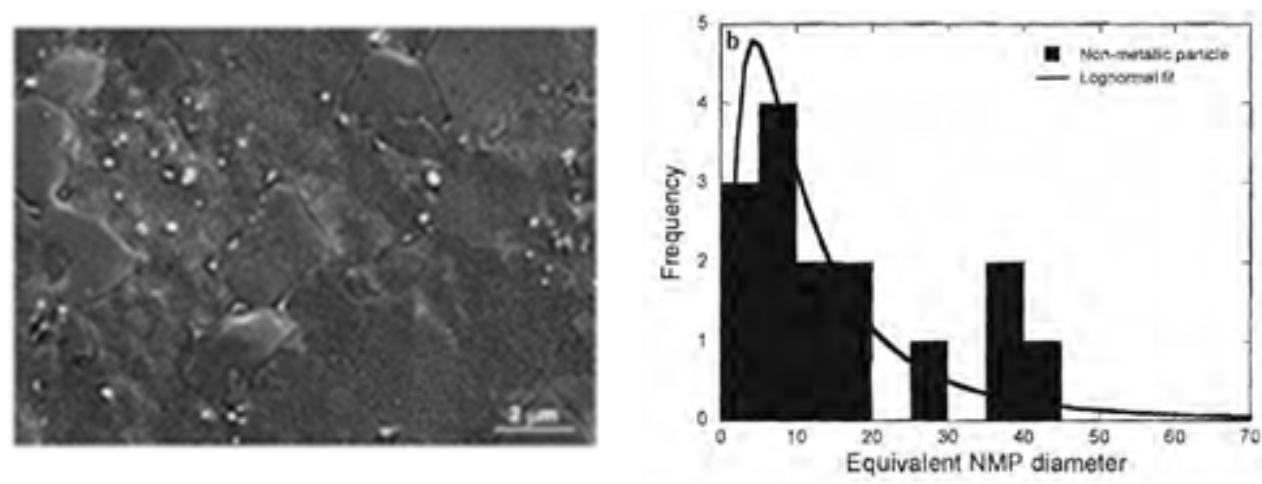

Fig. 3: (a) SEM image showing the spatial distribution of carbide inclusions (the white dots) [46], b) size distribution of the non-metallic inclusions/particles (NMP) [47].

\section{3D Finite Element Modelling of Notched Component}

The crystal plasticity model for nickel base superalloy presented in Section 2 is coded into ABAQUS 2006 UMAT. The notched geometry modeled in this work is a v-notched cylindrical component shown in Fig., 4. Different test cases are modeled which include: nickel base superalloy specimen without inclusion and nickel base superalloy specimen with inclusions at various orientations based on the distribution in Fig 3b. The material parameters for the nickel base superalloy in the crystal plasticity codes obtained from Musinski [48] and Przybyla et al. [49] are as presented in Table 1.

Table 1: Material parameters for crystal plasticity models [48-49]

\begin{tabular}{|c|c|c|c|c|c|c|}
\hline$\tau_{o, o c t}^{\alpha}(\mathrm{MPa})$ & $\tau_{o, c u b}^{\alpha}(\mathrm{MPa})$ & $c_{p 1}$ & $c_{p 2}$ & $c_{p 3}$ & $c_{g r}(\mathrm{MPa} \sqrt{\mathrm{mm}})$ & $\mathrm{n}_{\kappa}$ \\
\hline 85.1 & 170.2 & 1.351 & 1.351 & $1.22 * 10^{22}$ & 9.432 & 1 \\
\hline $\mathrm{b}_{\gamma^{\prime}(\mathrm{nm})}$ & $\mathrm{b}_{\gamma(\mathrm{nm})}$ & $\mu_{\gamma^{\prime}(\mathrm{MPa})}$ & $\mu_{\gamma(\mathrm{MPa})}$ & $k_{1}\left(m m^{-1}\right)$ & $k_{2}$ & $\rho_{\lambda, \mathrm{o}}^{\alpha}\left(\mathrm{mm}^{-2}\right)$ \\
\hline 0.25 & 0.41 & 81.515 & 130.150 & $2.6 * 10^{5}$ & 8.2 & $10^{5}$ \\
\hline$h_{o}$ & $h_{p c}$ & $h_{c b}$ & $h_{s c}$ & $\Gamma_{\mathrm{APB}}$ & $\eta_{o}$ & $k_{\delta}$ \\
\hline 4.8 or 2.4 & 0.8 & 0 & -0.4 & $1.64 * 10^{-3}$ & 2.82 & $2.5^{*} 10^{-3}$ \\
\hline$C_{11, \gamma^{\prime}}(\mathrm{MPa})$ & $C_{12, \gamma^{\prime}}(\mathrm{MPa})$ & $C_{44, \gamma^{\prime}}(\mathrm{MPa})$ & $C_{11, \gamma}(\mathrm{MPa})$ & $C_{12, \gamma}(\mathrm{MPa})$ & $C_{12, \gamma}(\mathrm{MPa})$ & $n_{1}$ \\
\hline
\end{tabular}




\begin{tabular}{ccccccc}
\hline 135,000 & 59,210 & 81,515 & 158,860 & 73,910 & 130,150 & 15 \\
& & & & & \\
\hline$n_{2}$ & $\dot{\gamma}_{1}\left(s^{-1}\right)$ & $\dot{\gamma}_{1}\left(s^{-1}\right)$ & $D^{\alpha}(\mathrm{MPa})$ & & \\
& & & & & \\
\hline 9 & 8.7 & $3.9 * 10^{-11}$ & 150 (oct) & & \\
& & & 180 (cub) & \\
\hline
\end{tabular}

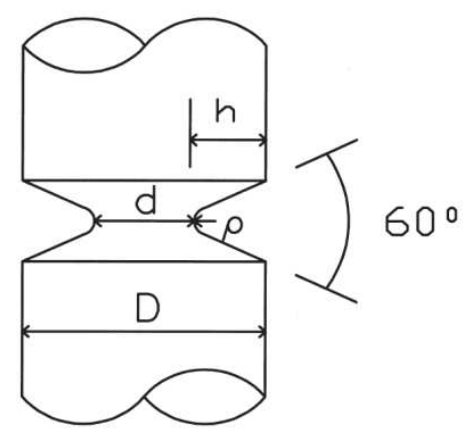

Fig. 4: cylindrical specimen with a circumferential V-notch

For the notched component without non-metallic inclusions, due to symmetry in geometry and loading, only one-quarter of the notched cylindrical geometry is modeled. Three different notch root radii and acuities are modeled to investigate the effect of notch root radius on the fatigue notch factor of the notched specimens. The dimensions of the three test cases modeled are as given in Table 2.

Table 2: Dimensions of the notched specimens

\begin{tabular}{lllll}
\hline $\begin{array}{l}\text { Test } \\
\text { Case }\end{array}$ & $\mathrm{D}(\mathrm{mm})$ & $\begin{array}{l}\text { Notch radius, } \\
\rho(\mathrm{mm})\end{array}$ & Notch depth, h $(\mathrm{mm})$ & R-ratio \\
\hline 1 & 5 & 0.150 & 0.142 & 0.1 \\
2 & 5 & 0.213 & 0.267 & 0.1 \\
3 & 5 & 0.284 & 0.714 & 0.1 \\
\hline
\end{tabular}

To determine the optimum element size to use for meshing the $3 \mathrm{D}$ model, mesh refinement study was conducted using a cube specimen subjected to $568 \mathrm{MPa}$ which is one of the loads applied to the specimens according to the experimental data obtained from Weiju et al. [50]. The von-Mises stress converged at an element size of $64 \mu \mathrm{m}$ and thus element size of $64 \mu \mathrm{m}$ is used in meshing all the nickel base superalloy specimens modeled. It is noted that the $64 \mu \mathrm{m}$ falls within the range of grain size for nickel base superalloy which normally vary from $30 \mu \mathrm{m}$ to $70 \mu \mathrm{m}$ [51]. The model is meshed using 3D stress four-node linear tetrahedron 
element type (C3D4). The bottom of the model is encastre and symmetry boundary conditions are applied on the planes of symmetry of the geometry.

For the notched components with non-metallic inclusions, the lognormal distribution of the inclusions in the nickel base superalloys shown in Fig. $3 \mathrm{~b}$ is taken into consideration. It is assumed that the shape of the inclusions is elliptical with different aspect ratios. The MC inclusions are assigned linear elastic material properties with Young's modulus $405 \mathrm{GPa}$ and a Poisson's ratio of 0.14 [36]. Here, the full geometry is modelled because there is no symmetry in the geometry due to presence of inclusions though symmetry is still maintained in the load application. The model is meshed using 3D stress four-node linear tetrahedron element type (C3D4) of size $64 \mu \mathrm{m}$ as early established by the mesh refinement study. The inclusions are randomly distributed with different orientations as illustrated in Fig. 5.
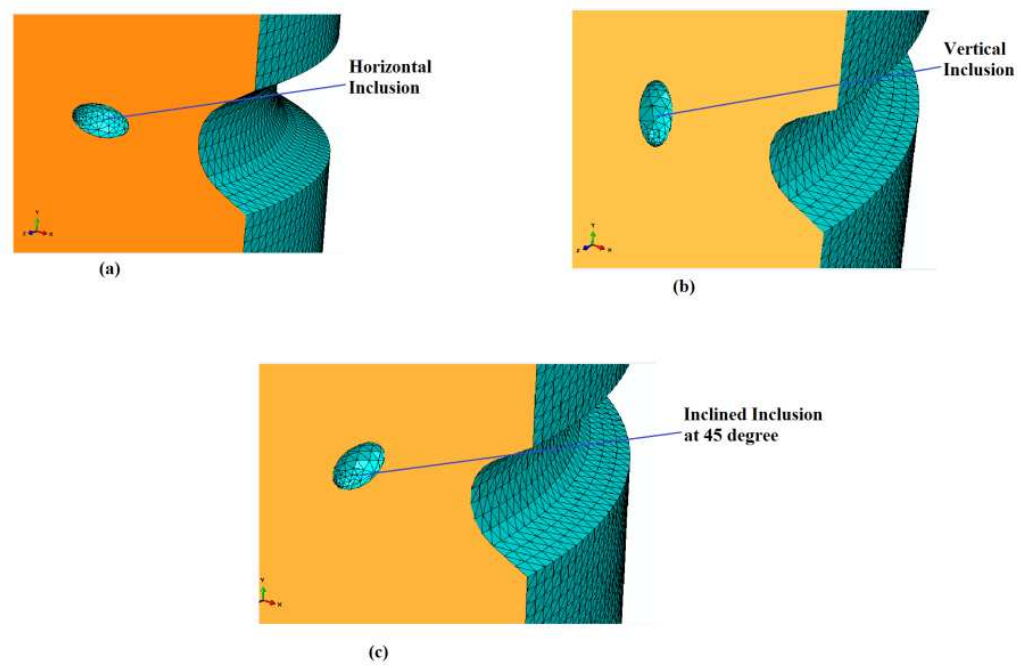

Fig. 5: Different orientation of inclusions in the matrix.

\section{Fatigue Damage Process Zone}

Attempts have been made by different researchers to succinctly define the fatigue damage process zone [52-54]. In general, the fatigue damage process zone is a volume comprising of pre-fracture zones in the vicinity of the notch, inclusion or any other stress raisers identified in the material. The pre-fracture zone is normally due to the detrimental effects of the stress raisers. To accurately predict life in $\mathrm{HCF}$, it is of paramount importance to be able to define the fatigue damage process zone with some level of precision. According to Ostash et al. [53], the fatigue 
damage process zone is defined as some volume in the bulk material in which macro- and micro-plastic strains take place which also serve as source of initial damage of the material microstructure. Some of the factors that affect the size of the fatigue damage process zone include material properties, loading amplitude, and environment.

The fatigue damage process zone used in this work is an extension of the fatigue damage process zone as defined by Owolabi et al. [55]. The fatigue damage process zone is defined based on the distribution of stress within the material. The statistical distribution of stress around the notch root and inclusions is used as a new criterion in defining the fatigue damage process zone. It is based on the assumption that the fatigue damage process zone is a region around the notch and inclusions having grains with stress values equal to or greater than a specified microscopic threshold value as shown in Fig. 6. Here, the yield stress of the material is specified as the microscopic threshold value.

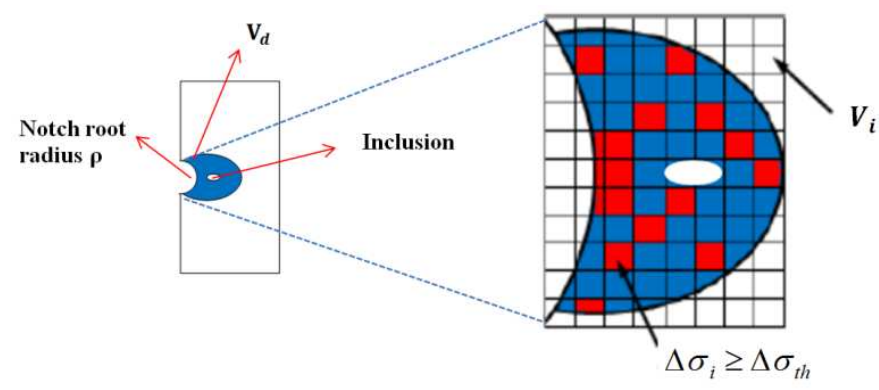

Fig. 6: Schematic of fatigue damage process zone.

\section{Probabilistic Framework for Fatigue Notch Factor}

The probabilistic models in Section 1 can be used to predict scatter of fatigue data and the dependence of fatigue limits on fatigue damage process zone. The predictive capabilities of these models can be enhanced by incorporating information regarding the origin of the scatter such as due the presence of defects and micro-scale plastic deformation using the crystal plasticity framework presented in Section 2. Using the stress distribution obtained from the crystal plasticity model, a weakest-link probabilistic framework is presented here to obtain the fatigue notch factor and the probability of formation of small crack following the framework presented in [56] with a few modifications based on the physical mechanisms of fatigue crack formation and growth for aero-engine materials with 
inclusions. As stated earlier, IN 100 contains nonmetallic inclusions and pores that play a critical role in the component's failure. Fatigue is manifested by extremal microstructure attributes that promote slip intensification and hence does not conform to homogenization. Thus, a probabilistic formulation to determine the failure potency in heterogeneous materials should include a consideration for these defects. This study combined the framework in [56] with other existing probabilistic formulations that consider the size distribution and proximity of defects and different competing damage mechanisms for IN 100.

For a smooth specimen with defects having a fatigue damage process zone of volume $\mathrm{V}$, the whole volume is divided into small volume elements, $\mathrm{dV}$ with probability of failure of a sufficiently small volume element given as:

$d P=\lambda d V$

Where here, $\lambda$ is the critical defect density defined as the expected number of defects per unit volume of the smooth specimen. Using weakest link theory, the probability of survival of the entire volume is obtained from the probability of survival of all " $j$ " number of sub-volumes i.e.:

$P_{s}=\prod_{i=1}^{j}\left(1-d P_{i}\right)=\prod_{i=1}^{j}(1-\lambda d V)$

This equations assumes that the defects are randomly distributed within the volume and thus do not interact, which is only reasonable when considering the formation of a fatigue $\operatorname{crack}(\mathrm{s}) \mathrm{HCF}$ and very high cycle fatigue (VHCF) regimes. As the volume of each small element tends to zero, equation (31) can be transformed into:

$P_{s}=\exp \left(-\int_{V_{d}} \lambda d V\right)$

Using the generalized extreme value distribution function, the distribution of defects, $a$, that are above the threshold, $\mathrm{a}_{\mathrm{th}}$, is modeled by a power law of the form 
$\lambda=\frac{1}{V_{0}}\left(1+\xi\left(\frac{a-a_{t h}}{a_{0}}\right)\right)^{-1 / \varepsilon}$

Where $\mathrm{a}_{0}$ and $\xi$ are the scale and shape parameters respectively. Substituting (33) into (32) yields:

$P_{s}=\exp \left\{-\frac{1}{V_{0}} \int_{V_{d}}\left(1+\xi\left(\frac{a-a_{t h}}{a_{0}}\right)\right)^{-1 / \varepsilon} d V\right\}$

If $a_{t h}=a_{0}^{*} \xi$, re-arranging equation (34) yields,

$$
P_{s}=\exp \left\{-\frac{1}{V_{0}} \int\left(\frac{a}{a_{0}^{*}}\right)^{-1 / \varepsilon} d V\right\}
$$

where $\mathrm{a}_{0}{ }^{*}$ is regarded here as the mean defect size. Equation (35) is valid only if $\xi \neq 0$. The critical defect size is related to the microscopic stress (taking here as a random variable) through a power law relationship of the form:

$$
\sigma_{a}=\frac{A}{\sqrt[z]{a}}
$$

Where $\mathrm{A}$ and $\mathrm{z}$ are materials constants. Similarly, the stress amplitude, $\sigma_{0}$ corresponding to the mean defect size $\mathrm{a}_{0}{ }^{*}$ can be taken as the fatigue limit of the reference volume $V_{\mathrm{o}}$ for $50 \%$ failure probability. The two parameters can also be related by a power law of the form:

$$
\sigma_{0}=\frac{A}{\sqrt[z]{a_{0}^{*}}}
$$


Combining Eqs. (36) and (37) we have:

$$
\frac{a}{a_{0}^{*}}=\left(\frac{\sigma_{0}}{\sigma_{a}}\right)^{z}
$$

Substituting Eq. (38) into Eq. (35) yields:

$$
P_{s}=\exp \left\{-\frac{1}{V_{0}} \int\left(\frac{\sigma_{a}}{\sigma_{0}}\right)^{b} d V\right\}
$$

where $\mathrm{b}=\mathrm{z} / \xi$. If $\sigma_{a}=\sigma-\sigma_{t h}$, Eq. (39) becomes:

$$
P_{s}=\exp \left[-\frac{1}{V_{0}} \int_{V_{d}}\left(\frac{\sigma-\sigma_{t h}}{\sigma_{0}}\right)^{b} d v\right]
$$

For $\xi>0, b, \sigma_{\text {th }}$ and $\sigma_{0}$ represents a 3-parameter Weibull shape, location and scale parameters. The cumulative probability of $\mathrm{HCF}$ failure of the component, specifically defined can be obtained from Eq. (40) as:

$$
P_{f}=1-\exp \left[-\frac{1}{V_{0}} \int_{V_{d}}\left(\frac{\sigma-\sigma_{t h}}{\sigma_{0}}\right)^{b} d v\right]
$$

To facilitate development of the expression for fatigue notch factor from Eq. (41), the concept of stress homogeneity factors is used. Thus Equation (41) can be rewritten as: 
$P_{f}=1-\exp \left[-\frac{k V_{d}}{V_{0}}\left(\frac{\sigma_{\max }}{\sigma_{0}}\right)^{b}\right]$

where

$k=\frac{1}{V_{d}} \int_{V_{d}}\left(\frac{\sigma-\sigma_{t h}}{\sigma_{\max }}\right)^{b} d v$

is regarded as the stress homogeneity factor. Conventionally, the fatigue notch factor is the ratio of smooth to notched fatigue strength at the same probability of failure (usually 50\%). Using Eq. (42), the probability of failure of smooth specimen and a notched specimen will be the same when:

$\exp \left\{-\frac{k_{s} V_{s}}{V_{o}}\left(\frac{\sigma_{\max , s}}{\sigma_{0}}\right)^{b}\right\}=\exp \left\{-\frac{k_{n} V_{n}}{V_{o}}\left(\frac{\sigma_{\text {max }, n}}{\sigma_{0}}\right)^{b}\right\}$

where the subscripts $n$ and $s$ represent the respective value of the variable for notched and smooth specimens. The ratio of the smooth to notch fatigue driving force parameters (i.e., the stress amplitude) is used to define a new fatigue notch factor given as:

$k_{f}=\frac{\sigma_{\max , s}}{\sigma_{\max , n}}=\left(\frac{k_{n}}{k_{s}}\right)^{1 / b}\left(\frac{V_{n}}{V_{s}}\right)^{1 / b}$

For smooth specimen that is loaded at a very low stress or strain amplitude in the HCF regime, the number of critically stressed grains (or elements) is very small. Thus for the life limiting case in which only one grain or element is critically stressed above the threshold, $V_{s}=V_{e t}$ (i.e. volume of element or grain) and $k_{s}=1$; thus Equation (46) becomes: 


$$
\begin{aligned}
& k_{f}=\frac{\sigma_{\max , s}}{\sigma_{\text {max }, n}}=\left(k_{n}\right)^{1 / b}\left(\frac{V_{n}}{V_{e}}\right)^{1 / b} \\
& k_{f}=\left[\frac{1}{V_{d}} \int_{V_{d}}\left(\frac{\sigma-\sigma_{t h}}{\sigma_{\max , n}}\right)^{b} d v\right]^{1 / b}\left(\frac{V_{n}}{V_{e}}\right)^{1 / b}
\end{aligned}
$$

It is important to state that if the materials contain some pores or inclusions as the case of nickel base superalloy, Eq. 46 must be used.

In Eq. 41 there are three unknown parameters namely the shape, location and scale parameter. The location parameter otherwise called the threshold stress is taken as the yield strength of the material leaving two unknown parameters. The remaining two unknown parameters are estimated using the modified moment estimation (MME) technique [57]. Here, the first two sample moments are used i.e., the mean $\bar{\sigma}_{m}$ and the variance $\bar{\sigma}_{m}^{2}$ of the stress distribution $\sigma$. With modification of the expression obtained from Cohen and Whitten [57] to account for notch size effect, the mean and variance are given as:

$$
\begin{gathered}
\bar{\sigma}_{m}=\sigma_{t h}+\sigma_{0}\left(\frac{V_{0}}{V_{d}}\right)^{b} \zeta_{1} \\
\bar{\sigma}_{m}^{2}=\sigma_{0}^{2}\left(\frac{V_{0}}{V_{d}}\right)^{2 b}\left(\zeta_{2}-\zeta_{1}^{2}\right)
\end{gathered}
$$

In Equations 49 and 50,

$$
\zeta_{k}=\zeta(1+k b), k=1,2
$$

And $\zeta($ ) is the gamma function defined by the integral:

$$
\zeta(s)=\int_{0}^{\infty} t^{s-1} e^{-t} d t
$$


By solving Equations (49) and (50) simultaneously, the two parameters $\sigma_{0}$ and b are determined. The yield stress of the nickel base superalloy is $1045 \mathrm{MPa}$. From Equations (49) and (50), b is determined to be 15.6 while the scale parameter $\sigma_{0}$ is determined to be $2826.07 \mathrm{MPa}$. From the geometry of the specimens, the reference volume $\mathrm{V}_{0}$ is calculated to be $11.152 \mathrm{~mm}^{3}$.

\section{Results and Discussion}

Three different notch root radii and acuities simulated in ABAQUS are assigned ten different random realizations of grain orientations for each of the notch root radius. The stress distribution from the simulation of the notched nickel based super alloy is extracted around the notch root and inclusion regions and used in Eq. 41 to determine the probability of failure for each notch root radius and the results are as plotted in Fig. 7. The fatigue notch factor is determined using Eq. (46) and the associated notch sensitivity index q for each case is also computed. Figure 7, shows the combined effect of notch root radius and the grain orientation of nickel base superalloy on its probability of failure. It is observed that the probability of failure rapidly increases with increasing notch root radius. Also, it can be seen that the orientation of the nickel base superalloy grains plays a significant role in determining the probability of failure and susceptibility of the bulk material to fatigue failure. It is observed that the probability of failure for each notch root radius varies with grain orientations. For example, for nickel base superalloy with notch root of $0.284 \mathrm{~mm}$, the probability of failure ranges from 0.52 to 0.64 . Thus, notches with favorably oriented grains in the vicinity of the notch and inclusions exhibit higher probability of failure. 


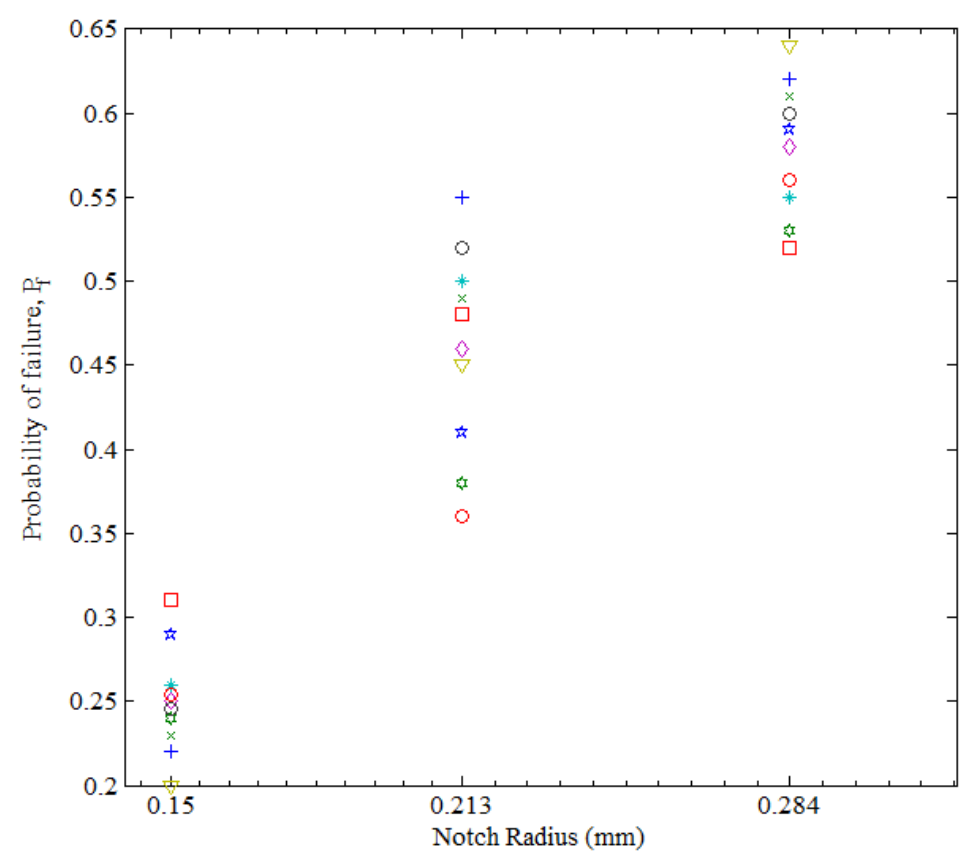

Fig. 7: Probability of failure vs notch root radius for notched nickel base superalloy specimens without inclusion.

Using Eq. (46), the associated microstructure dependent fatigue notch factors for the estimated probability of failures are computed and the average fatigue notch factor for each notch root radius is plotted as shown in Fig. 8 and compared with experimentally obtained fatigue notched factor from Weiju et al. [50] for nickel base superalloy. Figure 8 shows that the numerically obtained fatigue notch factors follow the same trend as the experimentally obtained values. The result also shows that the fatigue notch factor increases with increasing notch root radius. It can be inferred from the result that larger notch root radii are detrimental to fatigue failure of notched nickel base superalloy. The notch sensitivity index for both the experimentally determined $\mathrm{k}_{\mathrm{f}}$ and the $\mathrm{k}_{\mathrm{f}}$ determined using the newly developed probabilistic framework are computed and plotted as given in Fig. 9 for comparison purpose. Figure 9 shows that the notch sensitivity index follows the same trend as that of the experimentally determined value and increases with increasing notch root radius. 


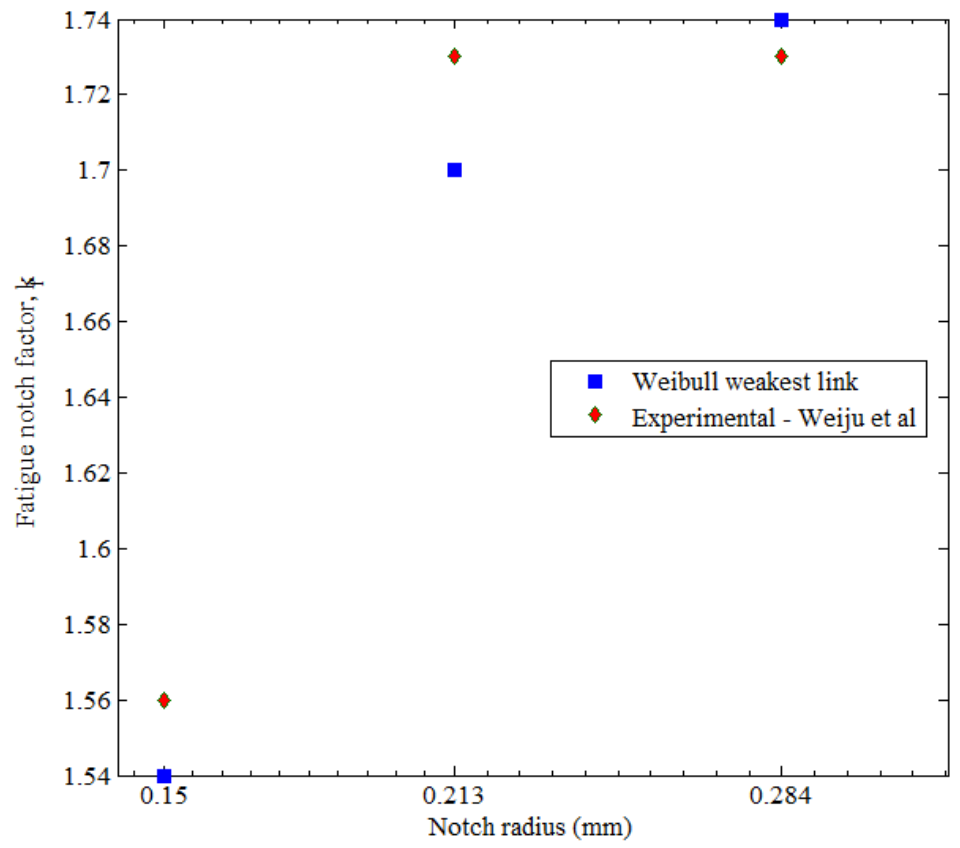

Fig. 8: Comparison of experimentally determined $\mathrm{k}_{\mathrm{f}}$ with the determine $\mathrm{k}_{\mathrm{f}}$ using the developed probabilistic framework.

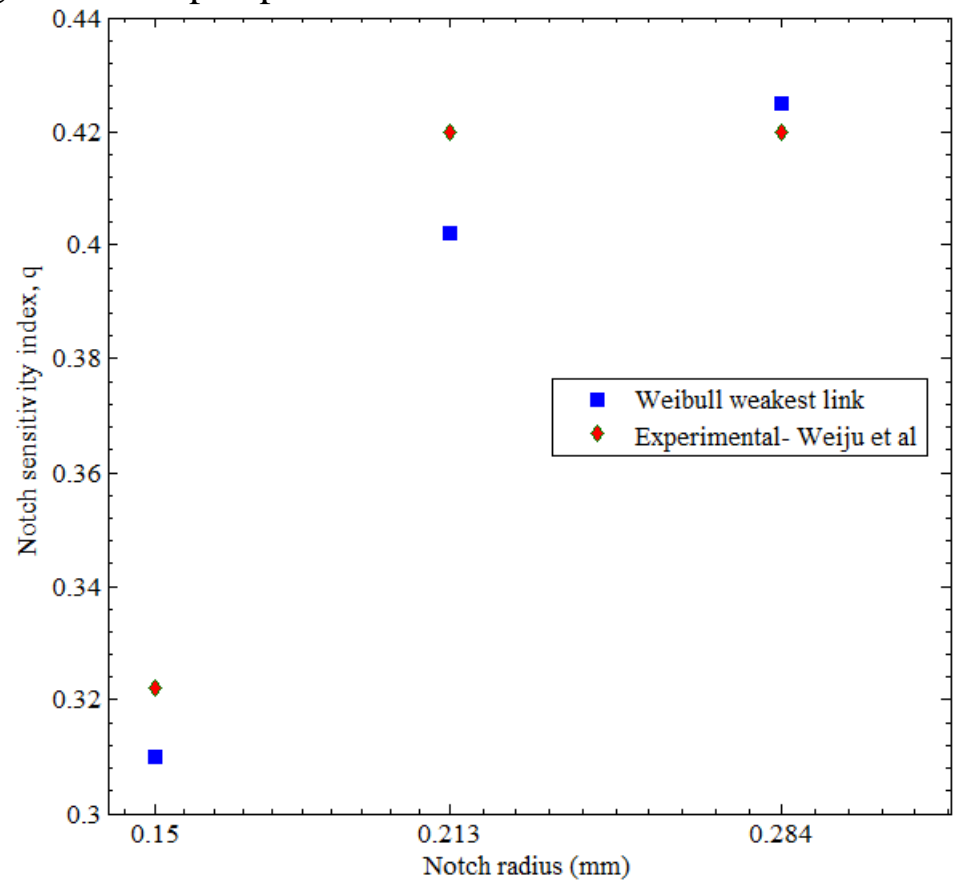

Fig. 9: Comparison of notch sensitivity index obtained from experiment and that obtained from developed model. 
The fatigue notch factor obtained using the probabilistic framework and closed form solution are plotted against the fatigue notch factor determined using existing conventional empirical methods such as the Neuber (Eq. 53), the Peterson [Eq. 54], and the Heywood [Eq. 55] models given respectively as:

$$
\begin{aligned}
& k_{f}=1+\frac{k_{t}-1}{1+\sqrt{\frac{a_{n}}{\rho}}} \\
& k_{f}=1+\frac{k_{t}-1}{1+\frac{a}{\rho}} \\
& k_{f}=1+\frac{k_{t}}{1+2 \sqrt{\frac{a}{\rho}}}
\end{aligned}
$$

where $k_{t}$ is the stress concentration factor and $a$ is a material constant. The results obtained using the various methods are shown in Fig. 10. The percentage variance/deviation of each method from the experimental value is presented in Table 3. The material constants for the empirical formulas in Eq. [53] to Eq. [55]

\begin{tabular}{|c|c|c|c|c|c|c|c|c|c|c|c|}
\hline \multirow{2}{*}{$\rho$} & \multirow{2}{*}{$\begin{array}{l}\text { Experiment } \\
\mathrm{K}_{\mathrm{f}}\end{array}$} & \multicolumn{2}{|c|}{ Weibull } & \multicolumn{2}{|c|}{ Neuber } & \multicolumn{2}{|c|}{ Peterson } & \multicolumn{2}{|c|}{ Heywood } & \multicolumn{2}{|c|}{ Closed form sol. } \\
\hline & & $\mathrm{K}_{\mathrm{f}}$ & $\%$ Var & $\mathrm{K}_{\mathrm{f}}$ & $\% \operatorname{Var}$ & $\mathrm{K}_{\mathrm{f}}$ & $\%$ Var & $\mathrm{K}_{\mathrm{f}}$ & $\begin{array}{l}\% \\
\text { Var }\end{array}$ & $\mathrm{K}_{\mathrm{f}}$ & $\%$ Var \\
\hline 0.150 & 1.56 & 1.54 & 1.28 & 1.61 & -3.21 & 1.54 & 1.28 & 2.56 & 64.10 & 1.58 & -1.28 \\
\hline 0.213 & 1.73 & 1.70 & 1.73 & 1.69 & 2.31 & 1.69 & 2.31 & 2.68 & 54.91 & 1.75 & -1.16 \\
\hline 0.284 & 1.73 & 1.74 & -0.58 & 1.74 & -0.58 & 1.80 & -4.05 & 2.77 & 60.12 & 1.78 & -2.89 \\
\hline
\end{tabular}
were obtained from [50].

Table 3: Percentage variance of $\mathrm{k}_{\mathrm{f}}$ from experimental value for different methods

Figure 10 and Table 3 shows that the probabilistic framework exhibits relatively lower percentage variance from experimental values compared to other existing conventional methods. Also, the closed form solution is also observed to give relatively accurate prediction compared to the existing classical methods as it has lower percentage variance from experimental results. The probabilistic framework 
and the closed form solution more accurately predict fatigue notch factor of notched nickel base superalloy compared to the existing conventional methods.

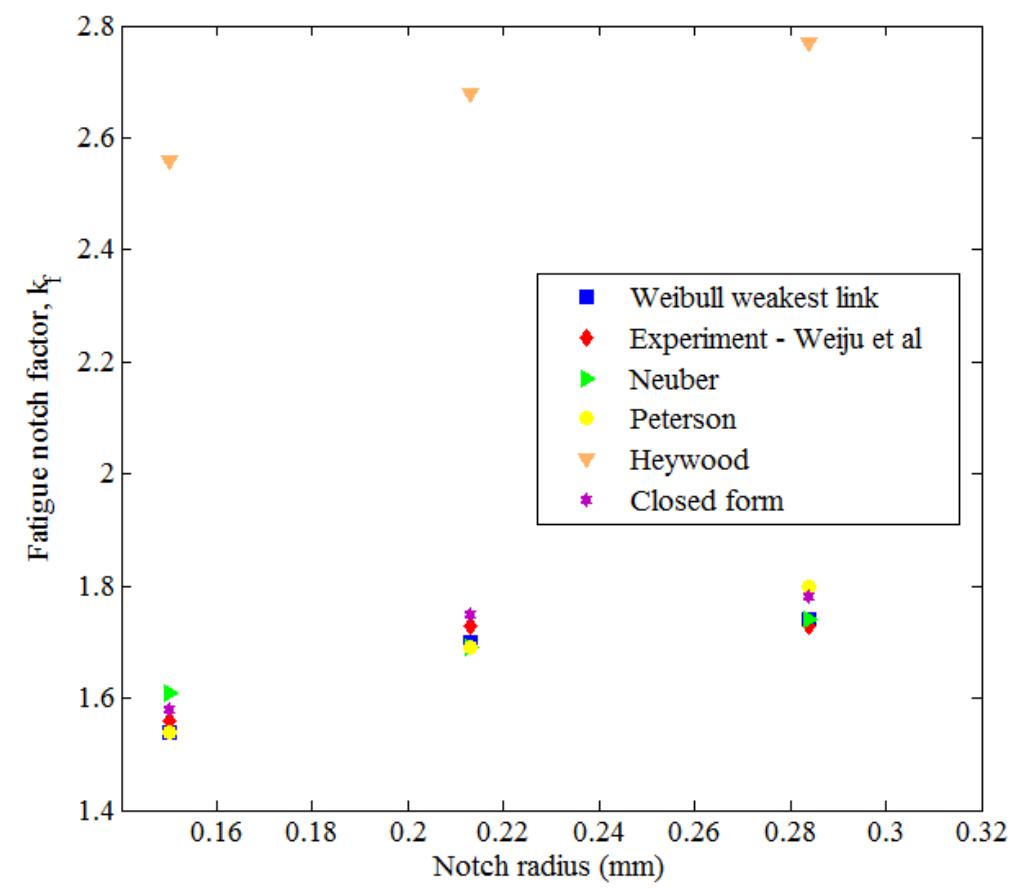

Fig. 10: Comparison of $\mathrm{k}_{\mathrm{f}}$ determined by the new model with existing conventional methods

For nickel-base superalloy with non-metallic inclusions, the $\mathrm{k}_{\mathrm{f}}$ is computed based on the stress distribution extracted from Abaqus for notch nickel base super alloy. Table 4 shows how the computed $\mathrm{k}_{\mathrm{f}}$ compare with the $\mathrm{k}_{\mathrm{f}}$ of notched nickel base superalloy without inclusions. Table 4 shows that the introduction of inclusions in the matrix of the notched nickel base superalloy increases the $\mathrm{k}_{\mathrm{f}}$. Thus component with inclusions of any kind will tend to have lower fatigue strength than components without inclusion. This is expected based on the fact that inclusions serve as favourable sites of premature plastic deformation due to high stress concentration in the vicinity of the inclusion curvature.

Table 4: Fatigue notch factor of nickel base superalloy with and without inclusion

\begin{tabular}{lll}
\hline$\rho$ & $\mathrm{k}_{\mathrm{f}}$ & \\
& Without Inclusion & With Inclusions \\
\hline 0.150 & 1.54 & 2.01 \\
0.213 & 1.70 & 2.38 \\
0.284 & 1.74 & 2.61 \\
\hline
\end{tabular}




\section{Conclusions}

A new probabilistic mesomechanics-based model was developed to obtain the fatigue notch factor, the associated notch sensitivity index and probability of forming microstructurally small for notched nickel base superalloy materials with and without non-metallic inclusions. The result shows that the probability of failure, the fatigue notch factor and associated notch sensitivity index all increase with increasing notch root radius. Also it is noted that the grain orientation of the material plays an important role in determining or predicting the fatigue strength of the material; the probability of failure varies at the same notch root radius for different grain orientation. The presence of inclusions around the fatigue damage process zone increases the fatigue notch factor of the notched nickel base superalloy.

\section{Acknowledgements}

The authors of this paper express their profound gratitude to the Department of Defense for the financial support provided through contract \# W911NF-11-1-041 (Dr. Ralph A. Anthenien, Program Manager, Army Research Office and Dr. David Stargel, Program Manager, Air Force Office of Scientific Research.)

\section{References}

[1] Tancret F. Quantitative modeling tools for the design of Ni-base superalloys. Processing for China. Sterling Publications, London 2000:56-58.

[2] Padula SA, Shyam A, Ritchie RO, and Milligan WW. High frequency fatigue crack propagation behavior of a nickel-base turbine disk alloy. International Journal of Fatigue 1999;21:725-731.

[3] Przybyla CP, Prasannavenkatesan R, Salajegheh N, and McDowell DL. Microstructure-sensitive modeling of high cycle fatigue. International Journal of Fatigue 2010; 32:512-525.

[4] Przybyla CP, McDowell DL. Simulation-based extreme value marked correlations in fatigue of advanced engineering alloys. Procedia Engineering 2010;2:1045-1052.

[5] Shenoy M, Zhang J, and McDowell DL. Estimating fatigue sensitivity to polycrystalline Ni-base superalloy microstructures using a computational approach. Fatigue and Fracture of Engineering Materials \& Structures 2007;30(10):889-904. 
[6] Raabe D, Roters F, Barlat F, Chen LQ. Continuum scale simulation of engineering materials: fundamentals-microstructures-process applications, 1st ed., Wiley-VCH, Weinheim 2004.

[7] Hyzak J, Bernstein I. Effect of defects on the fatigue crack initiation process in two P/M superalloys- 2. Surface-subsurface transition. Metallurgical Transactions. A, Physical Metallurgy and Materials Science 1982; 13A(1): 45-52.

[8] Deyber S., Alexandre F., Vaissaud J. Pineau A. Probabilistic life of DA718 for aircraft engine disks. Sixth International Symposium on Superalloys 718, 625, 706 and Derivatives, Warrendale, 2006.

[9] Efstratios N, Dan MG, Suren S. Engineering design reliability handbook, RC Press 2004.

[10]Deyber S, Alexandre F, Vaissaud J, and Pineau A, "Probabilistic life of DA718 for aircraft engine disks," in Sixth International Symposium on Superalloys 718, 625, 706 and Derivatives, Warrendale, 2006.

[11]. Tomkins B. Fatigue crack propagation-an analysis. Philosophical Magazine 1968;18:1041-1066.

[12] Pineau A. Superalloy discs durability and damage tolerance in relation to inclusions. Proceedings of a Conference on High Temperature Materials for Power Engineering 1990.

[13] Doudard C, Hild F, Calloch S. A probabilistic model for multiaxial high cycle fatigue. Fatigue \& Fracture of Engineering Materials \& Structures 2007;30:107-114.

[14] Gulino, R, Phoenix, SL. Weibull strength statistics for graphite fibres measured from the break progression in a model graphite/glass/epoxy microcomposite. Journal of Material Science 1991; 26:3107-3118.

[15] Denoual C and Hild F. Dynamic fragmentation of brittle solids: A multiscale model. Eur. J. Mech. A/Solids 2002; 21:105-120.

[16] Flaceliere L, Morel F.Probabilistic approach in high-cycle multiaxial fatigue: volume and surface effects.Fatigue \& Fracture of Engineering Materials and Structures 2004;27:1123-1135. 
[17] Papadopoulos IV. A high-cycle fatigue criterion applied in biaxial and triaxial out -of -phase stress conditions. Fatigue Fract. Engng Mater. Struct. 1995;18,7991.

[18] Delahay T, Palin-Luc T. Estimation of the fatigue strength distribution in high-cycle multiaxial fatigue taking into account the stress-strain gradient effect. International Journal of Fatigue 2006;28:474-484.

[20] Banvillet A, Palin-Luc T, Lasserre S. A volumetric energy based high cycle multiaxial fatigue criterion. Int. J Fatigue 2003;26(8):755 -769.

[21] Banvillet A, Palin-Luc T, Lasserre S, Vittori JF. Energy based high cycle multiaxial fatigue criterion depending on stress-strain distribution. Blom AF, editor. Eighth international fatigue congress, Fatigue 2002; Stockholm: EMAS: 283-290.

[22] Luai MA, Shaahid SM, Al-Mubarak AA, Jet impingement cooling in gas turbines for improving thermal efficiency and power density. Advances in Gas Turbine Technology 2011:191-210.

[23] Kupkovits RA. Thermomechanical fatigue behavior of the directionally solidified nickel-base superalloy CM247LC. MS Thesis, Georgia Institute of Technology 2008.

[24] Haritos GK, Nicholas T, Lanning DB. Notch size effects in HCF behavior of Ti-6Al-4V. Int. J. Fatigue 1999; 21:643-652.

[25] Yamashita Y, Ueda Y, Kuroki H, Shinozaki M. Fatigue Life prediction of small notched Ti-6Al-4V specimens using critical distance. Engineering Fracture Mechanics 2010; 77:1439-1453.

[26] Neuber HJ. Theory of stress concentration for shear-Strained prismatical bodies with arbitrary nonlinear stress-strain law. J. Appl. Mech. 1961;28(4):544 550 .

[27] Kuhn P, Hardraht HF, "An engineering method for estimating the notch-size effect in fatigue tests on steel. NACA TN2805 Langley Aeronautical Laboratory, Washington, 1952.

[28] Peterson RE. Notch sensitivity. Metal Fatigue, G. Sines and J. Waisman, Eds., New York, McGraw-Hill, 1959;293-306.

[29] Heywood RB. Stress concentration factors. Engineering 1955;179:146.

[30] Heywood RE. Design against fatigue, London: Chapman \& Hall 1962. 
[31] Buch A. Analytical approach to size and notch-size effect in fatigue of aircraft materials specimens. Material Science and Engineering 1974; 15:75-85.

[32] Buch A. Fatigue strength calculation, Switzerland: Trans Tech Publications 1998.

[33] Siebel E, Stieler M. Significance of dissimilar stress distributions for cycling loading. VDI - Zeitschrift 1955; 97(5):121-126.

[34] Ting JC, V. Frederick V., Lawrence FV Jr. Modeling the long-Life fatigue behavior of a cast aluminum alloy. Fatigue Fract. Eng. Mater. Struct. 1993;16:631647.

[35] Yu MT, DuQuesnay DL, Tooper TH. Int. J. Fatigue 1993; 15:109.

[36] Sheppard SD. Field effects in fatigue crack initiation long life fatigue strength. Failure Prevention and Reliability-89, ASME, New York 1989.

[37] Shenoy MM., Constitutive modeling and life prediction in nickel-base superalloys. Ph.D Thesis, Georgia Institute of Technology 2006.

[38] Kocks U, Argon A, Ashby M. Thermodynamics and kinetics of slip. Progress in Material Science, London: Pergamon Press, 1975.

[38] Ferney V, Hautefeuille M, and Clavel M. Multiaxial cyclic behavior in two precipitates strengthened alloys: Influence of the loading path and microstructure. Memoires et Etudes Scientifiques de la Revue de Metallurgie 1991; 88: 441-451.

[39] Heilmaier M, Leetz U,Reppich B. Order strengthening in the cast nickelbased superalloy IN100 at room temperature. Materials Science and Engineering 2001;A319-321:375-378.

[40] Reppich B, Schepp P, Wehner G. Some new aspects concerning particle hardening mechanisms in gamma prime precipitating nickel -base alloys; ii. Experiments. Acta Metallurgica 1982;30(1):95-104.

[41] Qin Q, Bassani JL. Non-schmid yield behavior in single crystals. Journal of Mechanics and Physics of Solids 1992;40: 813-833.

[42] Qin Q, Bassani JL. Non-associated plastic flow in single crystals. Journal of the Mechanics and Physics of Solids 1992;40:835-862.

[43] Shenoy MM, Gordon AP, Mcdowell DL, Neu RW. Thermomechanical fatigue behavior of a directionally solidified Ni-base superallloy. Journal of Engineering Materials and Technology 2005;127(3):325 - 336. 
[44] Feaugas X, Haddou H. Grain-size effects on tensile behavior of nickel and ANSI 316L stainless steel. Metallurgical and Materials Transactions A 2003;34: 2329-2340.

[45] Przybyla CP. Microstructure-sensitive extreme value probabilities of fatigue in advance engineering alloys. PhD Thesis, Georgia Institute of Technology 2010.

[46] Wusatowska-Sarnel AM, Blackburn HMJ, Aindow M. Techniques for microstructural characterization of powdered-processed nickel-based supperalloys. Materials Science and Engineering 2003;A360:390-395.

[47] Jha SK, Caton MJ, Larsen JM. Mean vs life limiting fatigue behavior of nickel-base superalloy. Part I: mechanisms, AFRL-RX-WP-TM-2010-4084.

[48] Musinski WD. Novel methods for microstructure-sensitive probabilistic fatigue notch factor. Master thesis Georgia Institute of Technology, Atlanta 2010.

[49] Przybyla CP and McDowell DL. Microstructure-sensitive extreme value probabilities for high cycle fatigue of Ni-base superalloy IN 100. International Journal of Plasticity 2010;26:372-394.

[50] Weiju R, Nicholas T. Notch size effects on high cycle fatigue limit stress of Udimet 720. Material Science and Engineering 2003; A357:141-152.

[51] Gayda J, Miner, RV. Fatigue crack initiation and propagation in several nickel-base superalloys at $650 \mathrm{o}^{\mathrm{c}}$. International Journal of Fatigue 1983;5(3): 135143.

[52] Ostash O.P, Panasyuk VV, Kosty EM. A phenomenological model of fatigue macrocrack initiation near stress concentrations. Fatigue and Fracture of Engineering Materials \& Structures 1999;22(2):161-172.

[53] Ostash OP, Panasyuk VV. Fatigue process zone at notches. International Journal of Fatigue 2001;23:627-636.

[54] Ranganathan RM, Gu RJ, Lee YL. An Improved automated finite element analysis for fatigue life predictions of notched components. International Journal of Materials Product and Technology 2004;21:539-554.

[55] Owolabi GM, Shi L, Whitworth H. A micromechanics-based fatigue damage process zone. Procedia Engineering 2011; 10:496-505.

[56]Okeyoyin OA and Owolabi GM. Application of weakest link probabilistic framework for fatigue notch factor to turbine engine materials. World Journal of Mechanics 2013; 5:237-244. 
[57] Cohen AC, Whitten BJ. Parameter estimation in reliability and life span models, New York: Marcel Dekker 1988. 
College of Engineering, Architecture and Computer Sciences

Department of Mechanical Engineering

\section{HOWARD \\ UNIVERSITY}

October 31, 2014.

The Editor-in-Chief

Engineering Fracture Mechanics

Dear Sir:

\section{Nomenclatures}

I wanted to inform you that the Nomenclatures are embedded in the main texts.

Yours very truly;

ours

Gbadebo Moses Owolabi, PhD, P.Eng.

(Assistant Professor) 